\title{
Interactions between sea urchin grazing and prey diversity on temperate rocky reef communities
}

\author{
Jarrett E. K. Byrnes, ${ }^{1,4}$ Bradley J. Cardinale, ${ }^{2,3}$ and Daniel C. Reed ${ }^{1}$ \\ ${ }^{1}$ Marine Science Institute, University of California, Santa Barbara, California 93101 USA \\ ${ }^{2}$ Department of Ecology, Evolution, and Marine Biology, University of California, Santa Barbara, California 93101 USA \\ ${ }^{3}$ School of Natural Resources and Environment, University of Michigan, Ann Arbor, Michigan 48109 USA
}

\begin{abstract}
While we frequently observe that increasing species richness within a trophic level can increase the rates of predation or herbivory on lower trophic levels, the general impacts of prey diversity on consumption rates by their predators or herbivores remains unclear. Here we report the results of two field experiments that examined how subcanopy sessile species richness affects rates of consumption by sea urchins. We crossed a natural gradient of species richness in a benthic subtidal community of understory macroalgae and sessile invertebrates against two experimental gradients of urchin density $(0-50$ and $0-14$ individuals) in $0.5-\mathrm{m}^{2}$ fenced plots. We found that the percent cover of macroalgae and invertebrates consumed by urchins was greater at higher levels of sessile prey species richness. However, this positive association between prey richness and sea urchin consumption was only apparent at low urchin densities; at high urchin densities nearly all algal and invertebrate biomass was consumed irrespective of sessile species richness. The positive relationship between prey richness and urchin consumption was also stronger when the abundance of prey species was more even (i.e., higher Simpson's evenness). Collectively, our results show that the consumptive impacts of urchins on kelp forest understory communities increases as a function of species diversity (both prey richness and evenness), but that prey diversity becomes irrelevant when urchins reach high densities.
\end{abstract}

Key words: giant kelp, Macrocystis pyrifera; grazer density; Mohawk Reef, Santa Barbara Channel, California; prey diversity; purple sea urchin, Strongylocentrotus purpuratus.

\section{INTRODUCTION}

Over the past decade, there has been an explosion of research examining how changes in biodiversity affect the ecological function and stability of ecosystems (see Hooper et al. [2005], Stachowicz et al. [2007], and Cardinale et al. [2012] for reviews). Hundreds of experiments have shown that changes in the richness of species within a given trophic group can have strong "top-down" effects that increase the consumption of resources by that trophic group (Balvanera et al. 2006, Cardinale et al. 2006, 2011, Worm et al. 2006). In contrast, the extent to which the diversity of prey acts as a "bottom-up" effect controlling their consumption by higher trophic levels is less well understood. In part, this lack of understanding is due to the inconsistency in the results of studies performed to date. Meta-analyses of decomposition experiments manipulating the species richness of dead organic matter (Srivastava et al. 2009) and meta-analyses of herbivory experiments manipulating plant species richness (Cardinale et al. 2011) both

Manuscript received 31 December 2011; revised 11 December 2012; accepted 2 January 2012; final version received 11 February 2013. Corresponding Editor: J. F. Bruno.

${ }^{4}$ Present address: Department of Biology, University of Massachusetts Boston, 100 Morrissey Road, Boston, Massachusetts 02125 USA. E-mail: jarrett.byrnes@umb.edu found a mixture of positive, negative, and neutral effects of prey richness on consumption. In contrast, metaanalyses by Hillebrand and Cardinale (2004) and Edwards et al. (2010) found that consumer effects tended to be smaller in magnitude in experiments with higher prey species richness. The divergent results of these two suites of meta-analyses illustrate that there is considerable uncertainty regarding the extent to which the diversity of prey alters their consumption by higher trophic levels. A greater understanding of the mechanisms that cause prey diversity to reduce or increase consumption is needed to resolve this uncertainty.

There are several mechanisms that might cause prey diversity to reduce consumption by higher trophic levels. The first mechanism, which we call the inedible prey sampling effect, occurs when diverse assemblages are more likely to contain inedible species (Steiner 2001). This mechanism can be particularly important if the inedible prey item is also numerically dominant in the prey community. Second, prey diversity can reduce consumption by increasing consumer search time. This mechanism is comparable to the "dilution effect" in disease ecology: transmission rates are reduced in a diverse community whenever the probability of contact between a pathogen and preferred host is reduced (Schmidt and Ostfeld 2001). Last, diversity may reduce consumption if diverse assemblages are more likely to 
host toxic or harmful epibionts (Wahl and Hay 1995) that prevent the consumption of other edible species present, a facilitation effect.

There are also several mechanisms by which prey diversity can enhance consumption. If highly edible or preferred prey species are more abundant in species-rich assemblages, then a positive relationship between prey diversity and consumption pressure is expected. Diversity can also enhance consumption if consumers require a balanced diet, either to meet their varied nutritional needs (Rapport 1971, Pennings et al. 1993, Wang et al. 2010), or to minimize the ingestion of toxic secondary compounds (Freeland and Janzen 1974, Pennings et al. 1993, Marsh et al. 2006). For these two mechanisms, consumption is expected to be higher when prey assemblages have a more even distribution of biomass among species (Illius et al. 1992, Pennings et al. 1993, Rogosic et al. 2007).

Here, we examine how the species richness of understory sessile prey items within a giant kelp forest affects their consumption by the purple sea urchin, Strongylocentrotus purpuratus. Loss of giant kelp (the urchins' primary food source) after storms typically leads to an increase in the diversity and abundance of competitively inferior sessile species on the reef (Arkema et al. 2009, Byrnes et al. 2011). In the absence of an abundant supply of living kelp or kelp detritus, urchins alter their behavior from passively feeding on drift-algae to actively roaming and scraping the bottom for attached algae and sessile invertebrates (Harrold and Reed 1985). This behavioral switch can lead to deforestation and the formation of what are commonly called "urchin barrens" (Harrold and Pearse 1987). If understory sessile species diversity affects urchin consumption rates, then it may influence the probability of urchin barren formation.

We examined the relationship between sessile prey species richness and urchin consumption in two separate field experiments in which we crossed a manipulated gradient of urchin density against a natural gradient of sessile species richness. Because we conducted these experiments in the field using natural assemblages, our experiments were also subjected to several biologically important, but unmanipulated variables: most notably, sessile species community composition and evenness. Therefore, we incorporated these unmanipulated variables into additional statistical analyses to further examine when species richness may influence consumption. Our decision to perform experiments in a natural setting with both controlled and uncontrolled sources of variation was an intentional choice. There have now been hundreds of studies (Cardinale et al. 2011) that have manipulated species richness under highly controlled, but contrived, conditions to examine how biodiversity influences ecosystem function (Duffy 2009). Such studies have proven incredibly valuable for suggesting potential mechanisms by which species richness may influence different ecosystem functions.
While these mechanisms may be important in nature, the artificial conditions of these previous experiments could limit their usefulness in evaluating the consequences of variation in prey species richness to the structure of natural communities (Bracken et al. 2008, Duffy 2009, Hillebrand and Matthiessen 2009). Such tightly controlled experiments are essential for progress in biodiversity research, but they must now be complimented by manipulations performed under more natural field conditions to fully understand the consequences of biodiversity change in nature. Because our experiments involved natural variation in diversity rather than experimentally manipulated levels we analyzed our data using an information criteria approach to assess the relative support of multiple a priori statistical models (Burnham and Anderson 2002). These models are subject to all of the same limitations in interpretation as analyses involving purely correlative data. Nevertheless, our analyses show that the sea urchin grazing was enhanced at high prey diversity, and that this relationship was weakened at high sea urchin density and low prey evenness. We show that variation in the effect of species richness on consumption is modified predictably by consumer pressure and prey community evenness.

\section{Methods \\ Experimental plots}

Both of our field experiments were performed in the summer of 2009 at $\sim 8 \mathrm{~m}$ depth within a $50 \times 50 \mathrm{~m}$ area of Mohawk Reef in the Santa Barbara Channel $\left(34^{\circ} 23^{\prime} 37^{\prime \prime} \mathrm{N}, 119^{\circ} 43^{\prime} 46^{\prime \prime} \mathrm{W}\right)$. The experimental area had all giant kelp (Macrocystis pyrifera) removed the preceding winter as part of an ongoing experiment to investigate the simulated effects of wave disturbance (Byrnes et al. 2011). We specifically chose this area because the removal of giant kelp led to an increase in the richness of the benthic community (Byrnes et al. 2011) consistent with the potential future effects of climate-induced changes in the frequency of intense storms that remove giant kelp. We were then able to use this gradient to test the effects of sessile species prey richness on urchin consumption and link the observed results to realistic shifts in diversity driven by climate change. Each experiment involved manipulating sea urchin abundance within fenced $0.5-\mathrm{m}^{2}$ plots framed with $2.5 \mathrm{~cm}$ diameter PVC pipe that was weighted with a steel core. Fences were $75 \mathrm{~cm}$ tall and made from $4-\mathrm{cm}$ mesh plastic Grip-Rite (PrimeSource Building Product, Irving, Texas, USA), They were fastened to the PVC pipe to form a flexible enclosure for containing urchins within the plots. The flexible nature of the fences allowed them to bend freely in the current, which dissuaded urchins from crawling over the top of the fences. A mesh skirt attached to the PVC pipe was anchored by $0.9 \mathrm{~cm}$ diameter chain to form a contoured barrier to the bottom that deterred urchins from crawling under the fence. Relatively few escapes were observed (92\% urchin retention after 2 weeks) and any 
escaped urchins were replaced halfway through each experiment (correlation coefficient between initial and final density over both experiments $=0.98$ ). The dominant caging artifact observed was a tendency for urchins at higher densities to climb the sides of cages if drift algae became caught in the mesh, potentially decreasing the grazing effects of urchins.

\section{Sampling sessile communities}

Each experiment consisted of three spatial blocks of 15 caged plots chosen to represent a wide range in sessile species richness. At the start of each experiment, we measured the percent cover and number of sessile algal and invertebrate species within each plot. We assessed percent cover and species richness using a fixed grid of 24 uniformly distributed points. We noted the species identity of all organisms encountered under each point. Using this method, a species could be counted multiple times under a single point, providing a more accurate estimate of the biomass of species that formed layers (e.g., the understory kelp Pterygophora californica). After surveying all 24 points, we recorded the number of species of macroalgae and sessile invertebrates not encountered in the point counts. We used these data and the identity of species from point counts to obtain a plot-wide measure of species richness. Species that were present in the plots, but not in contact with the grid of points, were assigned a percent cover value in the plot of $0.5 \%$.

Although purple sea urchins are generally considered to be herbivores, they frequently consume sessile invertebrates as well as algae (see extensive diet references in Byrnes et al. [2011]). Invertebrates may affect consumption rates by either providing associational defenses if they are unpalatable or toxic (Wahl and Hay 1995, Levenbach 2008), diluting preferred prey availability, or providing nutrients not found in algae (Fernandez and Pergent 1998). Thus we included both algae and sessile invertebrates in our measurements of prey abundance and richness in order to consider the full suite of potential effects of species richness on the magnitude of damage to the benthic community caused by urchin feeding.

\section{Experimental design}

The two experiments were similar in all aspects except in the range of sea urchin density tested. In the first experiment (hereafter referred to as the high-urchindensity experiment) urchin abundance ranged from 0 to 50 individuals per plot; this range corresponds to the natural range in urchin densities observed at Mohawk Reef and eight other reefs in the region during the period of 2001-2010 (data from the Santa Barbara Coastal Long Term Ecological Research project, available online). ${ }^{5}$ In particular, 50 urchins per plot (100 urchins $/ \mathrm{m}^{2}$ ) corresponded to the high densities observed

\footnotetext{
${ }^{5}$ http://sbc.lternet.edu
}

when urchins first moved into an area and transformed it into a barren. Results from this experiment suggested that prey diversity was only important at lower urchin densities (explained fully in Results). We therefore repeated the experiment using a gradient of urchin abundance ranging from 0 to 14 individuals per plot (hereafter referred to as the low-urchin-density experiment). This lower range of urchin abundance enabled us to examine the relationship between prey diversity and urchin consumption at low urchin densities with greater resolution.

We examined the consequences of prey species richness on urchin consumption in the field in each experiment using a factorial design that crossed the natural gradient in species richness against the full gradient observed in urchin density. This was done by grouping species richness and urchins into separate bins by amount, and then using these binned values to assign urchins to plots in a manner that created all possible combinations of urchin density and prey richness (see Appendix A for full design). Specifically, we grouped 15 levels of urchin density in each block of each experiment (i.e., $0,4,7,11,14,18,21,25,29,32,26,29,43,46$, and 50 urchins per plot in the high-urchin-density experiment and 0-14 urchins per plot in the low-urchindensity experiment) into five groups of three densities (e.g., 0, 4, and 7 urchins per plot; 11, 14, and 18; etc. in the case of the high-urchin-density experiment). Each of the 15 plots in each block was assigned to one of three groups of sessile species richness based on our initial surveys: low (10-16 species), medium (17-23), and high (24-30). We then randomly assigned each of the three members of an urchin density group to one of the three levels of species richness (Appendix A). For example for the lowest urchin density group in the high-urchindensity experiment, we placed 0 urchins in a low richness plot, 4 urchins in a high-richness plot, and 7 urchins in a medium-richness plot; for the next density group, we placed 11 urchins in a high-richness plot, 14 urchins in a low-richness plot, and 18 in a medium-richness plot; etc. This was repeated for each block of the experiment with the added stricture that each urchin density level had to be associated with at least one species richness group through the entire experiment. See Appendix A for the full treatment design. In both experiments, urchin test diameter averaged $57.21 \pm 9.73 \mathrm{~mm}$ (mean $\pm \mathrm{SD}$ ), which is within the range observed in other ecological studies of grazing by purple urchins (Behrens and Lafferty 2004). The percent cover (i.e., total number of points divided by 24) and richness of sessile species within each plot was sampled as described above both before and three weeks after introducing urchins to the plots to assess the impact of richness and urchin abundance on change in cover.

$$
\text { Analysis }
$$

We used an information-criterion-based model comparison approach (Burnham and Anderson 2002) to 
evaluate the association between sessile species richness and consumption pressure by urchins, defined as percent change in cover of the sessile community of algae and invertebrates over the course of the experiment. We used this model comparison approach rather than traditional null hypothesis testing as we were not strictly manipulating species richness, but rather used natural gradients that were already present (Burnham and Anderson 2002). From our data, we wished to assess the relative support for models that either did or did not incorporate a richness effect on change in sessile species cover. To assess the relative support for a richness effect, we fit five models to explain the observed change in the percent cover of sessile species over the duration of each experiment. Each model included initial point count cover as a covariate to control for its influence on the calculation of change in percent cover. The predictors in these models were (1) initial cover, (2) initial cover and urchin abundance, (3) initial cover and sessile species richness, (4) initial cover, sessile species richness, and urchin abundance, and (5) initial cover, sessile species richness, urchin abundance, and a richness $\times$ urchin interaction. Models were fit using least squares multiple linear regression, and diagnostics confirmed that models satisfied its assumptions. We compared the relative support for each model using model weights derived from their finite sample corrected Akaike's information criterion for small sample sizes $\left(\mathrm{AIC}_{\mathrm{c}}\right.$ ) values (Burnham and Anderson 2002). For the low-urchin-density experiment, we centered predictors (i.e., subtracted values from their means) before calculating the interaction in order to reduce variance inflation in reporting parameter estimation error. We performed a second test to ensure that our results were not due to a spurious negative correlation between species richness and amount of cover within a plot. To test this hypothesis, we fit a generalized linear model with a Gamma error distribution and a log link (McCullagh and Nelder 1989) using richness as a predictor of cover and compared it to a null model using $\mathrm{AIC}_{\mathrm{c}}$ weights. All analyses were done using $\mathrm{R}$ version 2.13 (R Development Core Team 2011).

\section{Analysis of uncontrolled sources of variation}

Because of our use of natural variation in species richness, we did not control for species composition or community evenness. Composition, either via the presence or absence of certain key species or functional groups, has been shown to be important for ecosystem function in many controlled manipulations of species richness (Tilman et al. 1997, Hector et al. 2011). Likewise, the evenness of species may influence the effects of species richness (Hillebrand et al. 2008); this may be particularly important when examining the effect of prey evenness on consumption (Illius et al. 1992, Pennings et al. 1993, Rogosic et al. 2007). We examined whether composition or evenness may have driven or influenced the relationship between species richness and change in percent cover in the low-urchindensity experiment.

We first examined whether the relationship between richness and cover was a result of either the cover of sessile invertebrates as a group, as they may have been less palatable than algae overall, or the cover of the four most abundant species ( $55 \%$ of points in initial surveys) found in plots: Pterygophora californica, Chondracanthus corymbiferus, Rhodymenia pacifica, and Muricea californica. If the cover of invertebrates or any of these species drove the relationship, they should also have a positive relationship with initial species richness. We therefore fit a generalized linear model with point count of species or group as a predictor of initial species richness using a Poisson error and a log link (see O'Hara and Kotze [2010] for a detailed discussion of regression with count data). We used point counts rather than percent cover as they captured absolute abundance of species or groups within a plot. We then examined the relative support for the existence of a relationship by comparing each fitted model to a null (i.e., cover of a species or group was unrelated to initial species richness) with $\mathrm{AIC}_{\mathrm{c}}$ model weights.

Second, we examined whether community evenness may have modified the effects of species richness on change in percent cover. We began by calculating the initial community evenness for each plot using Simpson's index (Smith and Wilson 1996). We then fit four alternative models to the data from the low-urchindensity experiment based on our previously selected best model. The predictor variables in these models were (1) richness and urchin abundance, (2) evenness and urchin abundance, (3) evenness, richness, and a richness $\times$ evenness interaction, and (4) urchin abundance, evenness, richness, and a richness $\times$ evenness interaction. We then compared them with $\mathrm{AIC}_{\mathrm{c}}$ model weights as before. To report coefficient estimates and estimation error, we centered predictors before calculating interactions as before.

\section{RESUlts}

\section{High-urchin-density experiment}

In the high-urchin-density experiment, we found a negative relationship between species richness and change in percent cover that attenuated at high urchin abundance. This result was seen in the model with the greatest support; of the models considered, $69 \%$ of the $\mathrm{AIC}_{\mathrm{c}}$ model weight support went to the model that included species richness, urchin abundance, and an interaction between the two (Table 1a, model $R^{2}=0.54$ ). Models not including an interaction between species richness and sea urchin abundance had little support (Table 1a). The model that included richness alone with no effect of urchins also had minimal support $\left(\mathrm{AIC}_{\mathrm{c}}\right.$ weight $\sim 0$ ), which was unsurprising given the strong grazing effect we observed.

The interaction effect between urchin abundance and species richness was manifested as species richness being 
TABLE 1. Akaike information criterion for small sample sizes $\left(\mathrm{AIC}_{\mathrm{c}}\right)$ weight table for models examining the predictive ability of richness, urchin abundance, and their interaction on change in percent cover of sessile species over three weeks of the experiment.

\begin{tabular}{lrrr}
\hline \hline \multicolumn{1}{c}{ Model } & & & \\
\hline $\mathrm{AIC}_{\mathrm{c}}$ & $\Delta \mathrm{AIC}_{\mathrm{c}}$ & $\begin{array}{c}\mathrm{AIC}_{\mathrm{c}} \\
\text { weight }\end{array}$ \\
\hline a) High-urchin-density experiment & & & \\
Cover & 419.95 & 25.67 & 0 \\
Urchins + cover & 397.27 & 2.99 & 0.15 \\
Richness + cover & 419.87 & 25.59 & 0 \\
Richness + urchins + cover & 397.27 & 2.99 & 0.15 \\
Richness $\times$ urchins + cover & 394.28 & 0 & 0.69 \\
b) Low-urchin-density experiment & & & \\
Cover & 274.92 & 9.33 & 0.00 \\
Urchins + cover & 271.81 & 6.23 & 0.02 \\
Richness + cover & 269.97 & 4.39 & 0.05 \\
Urchins + richness + cover & 265.67 & 0.09 & 0.45 \\
Richness $\times$ urchins + cover & 265.58 & 0.00 & 0.47 \\
\hline
\end{tabular}

Notes: All models included initial cover of sessile species (indicated as cover) as a covariate. Results are reported for the (a) high-urchin-density experiment and (b) low-urchin-density experiment. unrelated to change in percent cover at urchin abundances greater than $\sim 16$ urchins per plot (Fig. 1). We observed substantial decreases in the percent cover of algae and sessile invertebrates $(\sim 20-60 \%)$ that were driven solely by sea urchins when urchin abundance was greater than $\sim 16$ individuals per plot (Fig. 1). This effect of urchin density overwhelmed any relationship between species richness and change in cover, which can be seen by calculating predicted values using the coefficients in Table 2a. For example, this model produced a richnesspercent-cover relationship that was within 1 standard error of 0 at $>16$ urchins, but always less than 0 at $<16$ urchins. Only at these low urchin densities $(<16)$ was there any observed relationship to richness, with greater reduction in cover in plots with higher species richness (Fig. 1, Table 2a for coefficients). Our estimate of the richness $\times$ urchin interaction had a large standard error compared to its estimated effect size (Table 2a), although there was some support for the estimate being different from $0(t=1.66, P=0.10)$. The variability of this effect relative to its estimated size may have been due to the lower sample size at the low range of urchin densities (Appendix A) or other extrinsic factors

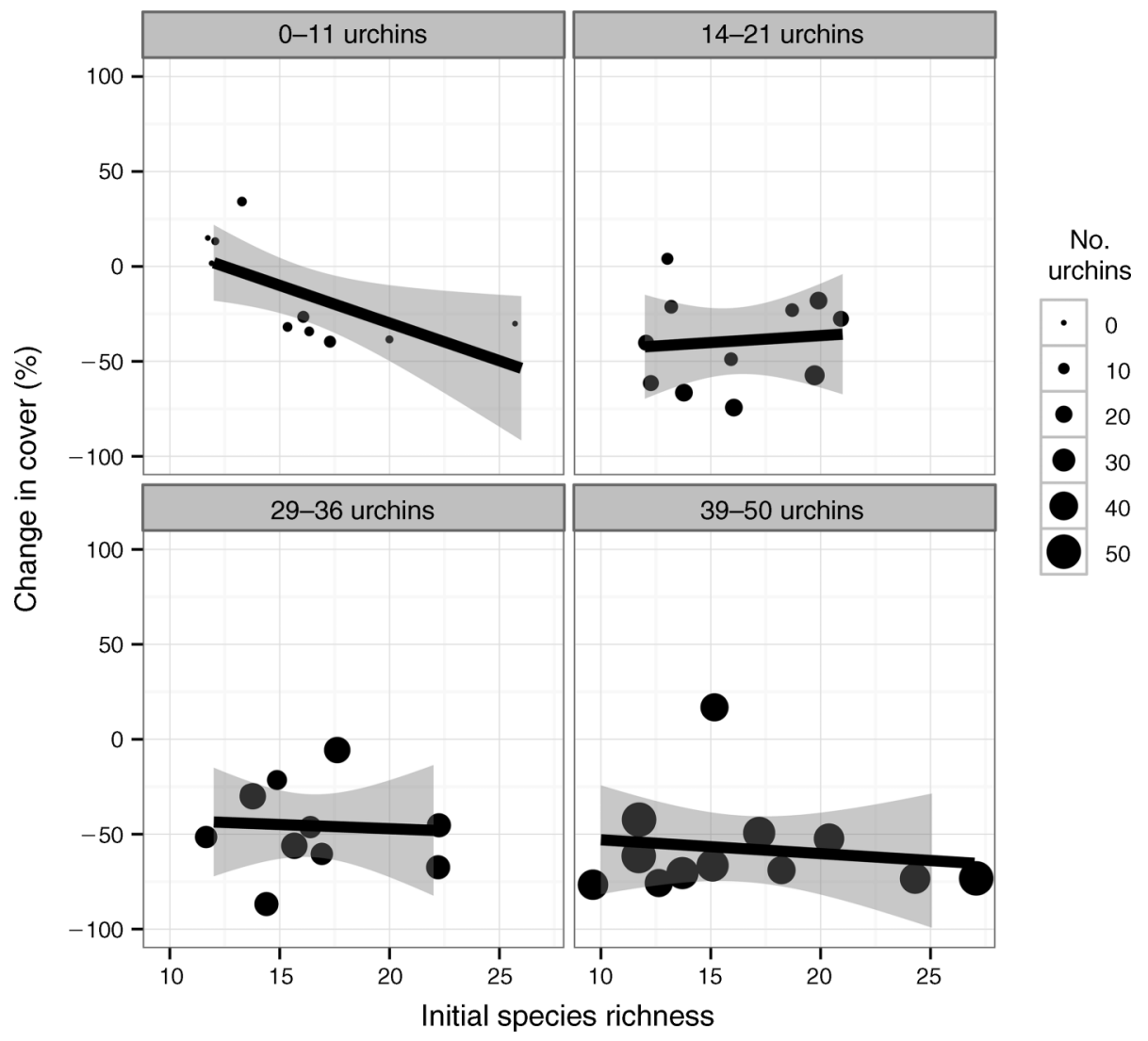

FIG. 1. Change in cover plotted against initial species richness for the high urchin density experiment. Data are split into four plots with each panel representing a subset of the data split evenly into four groups by urchin density $(0-11,14-21,29-36,39-50$ urchins). Point size is proportional to the abundance of urchins in a plot. Linear models were fit separately for each panel for visualization of the urchin abundance $\times$ species-richness interaction effect. Gray fill represents one standard error around the fitted line. 
TABLE 2. Coefficient estimates and their standard error for the selected model in the (a) highurchin-density experiment and (b) low-urchin-density experiment.

\begin{tabular}{lrrrr}
\hline \multicolumn{1}{c}{ Coefficient } & Estimate & SE & $t$ & $P$ \\
\hline a) High-urchin-density experiment & & & & \\
Intercept & 53.011 & 23.787 & 2.229 & 0.032 \\
Richness & -1.857 & 1.404 & -1.322 & 0.194 \\
Urchin abundance & -2.173 & 0.704 & -3.085 & 0.004 \\
Initial cover & -0.783 & 0.209 & -3.745 & 0.001 \\
Richness $\times$ urchin & 0.069 & 0.042 & 1.657 & 0.105 \\
b) Low-urchin-density experiment & & & & \\
Intercept & 60.396 & 19.071 & 3.167 & 0.004 \\
Richness & -2.501 & 1.046 & -2.390 & 0.024 \\
Urchin abundance & -1.737 & 0.881 & -1.971 & 0.059 \\
Initial cover & -0.527 & 0.230 & -2.290 & 0.030 \\
Richness $\times$ urchin & 0.065 & 0.238 & 0.275 & 0.786 \\
\hline
\end{tabular}

Note: Coefficients in the low-density experiment come from a model where richness and urchin abundance were centered before calculating the interaction effect to reduce variance inflation.

influencing the coefficient estimate. Thus we conducted a second experiment using only that lower range of sea urchin abundances in order to estimate the effect of richness at low urchin abundance. We also conducted analyses that incorporated other unmanipulated sources of variability in our plots (see Results: Uncontrolled sources of variation) to clarify the results.

\section{Low-urchin-density experiment}

In the low-urchin-density experiment, we found a negative relationship between sessile species richness and change in percent cover (Fig. 2, Table 2b), validating the richness $\times$ urchin interaction effect, that richness has a negative effect on change in cover at low urchin densities, in the high-urchin-density experiment. The models predicting changes in sessile species cover that included species richness + urchins and species richness $\times$ urchins received equal support (roughly $\sim 45 \%$ each with $R^{2}=0.40$ for the additive model and $R^{2}=0.38$ for the nonadditive model, thus capturing $92 \%$ of the model weight support between them, Table 1b). In both models, there was a negative relationship between species richness and change in percent cover $(-2.974$ in the model with an interaction vs. -2.500 in the additive model). The difficulty in distinguishing between the two models was due to the low estimated effect size and high variability of the estimate of the interaction coefficient such that the parameter estimate was within $1 \mathrm{SE}$ of 0 $(-0.065 \pm 0.238$ [mean \pm SE] $)$. Subsequent power analysis showed that the clear detection of an interaction effect using a range of $0-14$ urchins with the full 45 samples was unlikely (power estimated as 0.2 from simulation analysis using estimated parameters and variances from the high-density experiment), despite this model producing parameter estimates similar to those from the high-density experiment (compare Table 1 and Table 2). Additionally, recreational fishing at the site resulted in the removal of fences surrounding 14 of the 45 plots in the low-urchin-density experiment including two of the three 0 urchin control plots (i.e., hooks, lines, and other fishing gear were found attached to cages several meters from their original location), which further reduced power and increased residual variance. Because the effects of richness and urchins were not qualitatively different between the two models, we used the results from the interaction model (Table $2 b$ ) in order to be consistent with the results from the high-density experiment when exploring the effects of evenness.

Broadly, our results in the low-urchin-density experiment confirm our observations from the high-urchindensity experiment. Species richness of sessile species was negatively correlated with change in their percent cover (Fig. 2, Table 2b, $-2.736 \pm 1.106$ [mean \pm SE]) This result was not spuriously driven by low species richness occurring primarily in plots with high cover of sessile species. Rather, we observed a positive relationship between initial cover and initial species richness $\left(\mathrm{AIC}_{\mathrm{c}}\right.$ weight $=0.842$, coefficient $\left.=0.039 \pm 0.016\right)$ indicating that the negative effect of species richness on

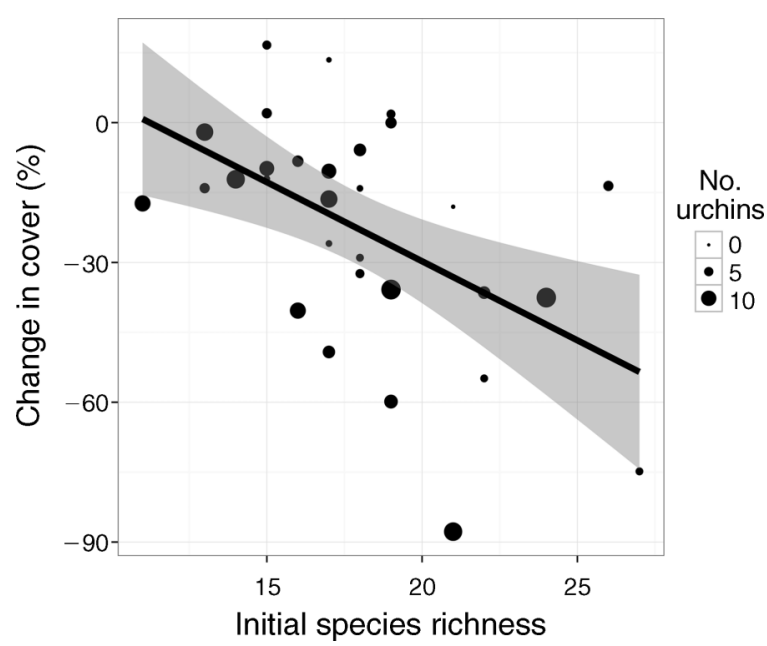

FIG. 2. Change in cover plotted against initial species richness for the low urchin density experiment. Point size is proportional to the number of urchins in a plot. Gray fill represents one standard error around the fitted line. 
TABLE 3. The $\mathrm{AIC}_{\mathrm{c}}$ weights of alternative hypotheses for the observed effects of urchin consumption in which the cover of individual species or groups influenced initial species richness.

\begin{tabular}{lccc}
\hline \hline \multicolumn{1}{c}{ Model } & $\mathrm{AIC}_{\mathrm{c}}$ & $\begin{array}{c}\Delta \mathrm{AIC}_{\mathrm{c}} \text { relative } \\
\text { to null }\end{array}$ & $\begin{array}{c}\text { Model weight } \\
\text { relative to null }\end{array}$ \\
\hline All invertebrates & 172.53 & 1.78 & 0.29 \\
Pterygophora & 171.30 & 0.55 & 0.43 \\
Chondracanthus & 172.98 & 2.23 & 0.25 \\
Rhodymenia & 172.89 & 2.14 & 0.26 \\
Muricea & 172.81 & 2.06 & 0.26 \\
\hline
\end{tabular}

Note: All weights are presented relative to the null model that initial species richness was unrelated to the cover of any species or species group.

decrease in percent cover was independent of the percent cover of sessile species at the start of the experiment. This result is the opposite of that expected if a negative correlation caused the observed richness effect. We note that urchins did appear to have an effect on cover $(P=$ 0.059 , Table 2). This was consistent with observations of grazing scars and excised areas on fleshy algae and invertebrate colonies in all experimental plots.

\section{Uncontrolled sources of variation}

While we were not able to detect an effect of prey species composition (abundance of common species or abundance of invertebrates) on our results, species evenness appeared to affect the relationship between richness and change in percent cover; the negative relationship was stronger in more even assemblages. Models that examined whether the richness-cover relationship was driven by the abundance of sessile invertebrates or the cover of the four of the most prevalent species in the experiment had less support than a null model $\left(\mathrm{AIC}_{\mathrm{c}}\right.$ weight $<0.5$ in all cases, Table 3$)$. Comparison of models incorporating species evenness showed that the vast majority of model weight supported models with an interaction between richness and evenness $(99.6 \%$ of model weight support for models including a richness $\times$ evenness interaction, Table 4). In these models the interaction between richness and evenness resulted in species richness having a stronger relationship with change in percent cover at higher levels of evenness (Table 5, Fig. 3). The model with an evenness $\times$ richness $\times$ urchin interaction received the most support (78\%), although, interactions involving urchins were not detectably different from 0 even after centering predictors before calculating interaction effects $(P>0.23$ for all, Table 5). Again, this was likely due to power limitations at this lower range of urchin abundances.

\section{DisCUSSION}

To fully understand the consequences of changes in prey biodiversity, we need to know when, where, and how prey diversity loss will influence consumption by higher trophic levels. The results of experiments examining the effects of prey diversity on consumption have thus far been mixed. On one hand, many individual experiments have shown that prey diversity can reduce consumption (e.g., Steiner 2001, Hughes and Stachowicz 2004, Duffy et al. 2005, Gamfeldt et al. 2005, Wyckmans et al. 2007, Bruno et al. 2008, Parker et al. 2010). Other experiments have shown little or no effect of prey diversity on consumption rates (Pfisterer et al. 2003, Fox 2004, Scherber et al. 2006). As a result, meta-analyses that have examined the extant data regarding the impact of prey/resource diversity on herbivory/detritivory have shown no net effect (Srivastava et al. 2009, Cardinale et al. 2011). However, these meta-analyses have seldom controlled for confounding effects of other ecological drivers. Our results show that prey diversity can have different consequences depending on consumer pressure and prey community evenness. The lack of a clear answer thus far could be due to additional unexamined variation between experiments. The results of our experiments demonstrate how the effects of prey diversity on consumption can be altered predictably by additional ecological factors.

In our experiments, the diversity of sessile benthic prey was associated with an increase in loss of prey abundance when urchin density, and thus net consumer pressure, was low. At low urchin densities, our fitted models show that an increase in approximately five prey species reduced prey cover by up to $15 \%$ (Fig. 2). At high densities, generalist urchins appeared to consume as much as possible and prey species diversity was unimportant, much like results demonstrating the decrease in facilitation effects of anemones for algal turfs at high urchin densities (Levenbach 2008). This conclusion is strengthened by the fact that we observed this phenomenon in two independent experiments. Our findings did not appear to result from the abundance of any particular common species or less palatable sessile invertebrates. However, we did find that the effect of richness on loss of cover was stronger in more evenly mixed assemblages, which suggests that the impacts of prey richness on change in prey abundance are influenced by both urchin density and prey evenness.

TABlE 4. $\mathrm{AIC}_{\mathrm{c}}$ weight table for models examining the predictive ability of sessile species richness, sessile species evenness, urchin abundance, and the interaction between all three on change in percent cover in the sessile benthic biota following three weeks of urchin grazing in the low-urchindensity experiment.

\begin{tabular}{lcrc}
\hline \hline \multicolumn{1}{c}{ Model } & $\mathrm{AIC}_{\mathrm{c}}$ & $\Delta \mathrm{AIC}_{\mathrm{c}}$ & $\begin{array}{c}\mathrm{AIC}_{\mathrm{c}} \\
\text { weight }\end{array}$ \\
\hline Richness + urchins + cover & 265.67 & 11.01 & 0.00 \\
Evenness + urchins + cover & 269.93 & 15.27 & 0.00 \\
Evenness $\times$ richness + cover & 262.28 & 7.61 & 0.02 \\
Evenness $\times$ richness + urchins & 257.36 & 2.70 & 0.20 \\
$\quad+$ cover & & & \\
$\quad \begin{array}{l}\text { Evenness } \times \text { richness } \times \text { urchins } \\
\quad+\text { cover }\end{array}$ & 254.67 & 0.00 & 0.78 \\
\hline
\end{tabular}

Note: All models included initial cover (point counts) as a covariate. 
TABLE 5. Coefficient estimates and their standard error for the urchin abundance $\times$ richness $\times$ evenness model of change in sessile species percent cover in the low-urchin-density experiment.

\begin{tabular}{lrrrr}
\hline \hline \multicolumn{1}{c}{ Coefficient } & Estimate & \multicolumn{1}{c}{ SE } & \multicolumn{1}{c}{$t$} & $P$ \\
\hline Intercept & 0.752 & 3.244 & 0.232 & 0.819 \\
Evenness & -69.409 & 69.390 & -1.000 & 0.328 \\
Richness & -1.890 & 1.192 & -1.585 & 0.127 \\
Urchin abundance & -2.217 & 0.933 & -2.378 & 0.027 \\
Initial cover & -1.003 & 0.377 & -2.662 & 0.014 \\
Evenness $\times$ richness & -44.959 & 14.911 & -3.015 & 0.006 \\
Evenness $\times$ urchin abundance & -1.937 & 13.995 & -0.138 & 0.891 \\
Richness $\times$ urchin abundance & 0.067 & 0.271 & 0.247 & 0.807 \\
Evenness $\times$ richness $\times$ urchin abundance & 5.462 & 4.480 & 1.219 & 0.236 \\
\hline
\end{tabular}

Note: Richness, evenness, and urchin abundance were centered before calculating the interaction effects to reduce variance inflation.

Perhaps the clearest result of our work is that when consumer density was extremely high, prey diversity had no effect on the amount of the prey assemblage consumed. Given the large potential impact of high densities of sea urchins on the benthic community (Harrold and Reed 1985, Harrold and Pearse 1987) and their generalist diet (Byrnes et al. 2011), we find this result unsurprising. Prey community properties should only affect total consumption if consumers are able to at least meet their basal metabolic demands or toxicity is high enough to stymie consumption. Based on our results, we suggest that negative effects of prey diversity on consumption may be more prevalent when consumers are not limited by the amount of available prey.
Similarly, the diversity-consumption relationship might change in magnitude or sign at higher consumer abundance as variation in prey quality becomes less important and extreme toxicity becomes more important. Future experiments should consider the effects of consumer pressure in their design and analysis; future meta-analyses might wish to consider some measure of relative consumer pressure as well.

Our results also show that evenness can affect the outcome of prey diversity experiments. This effect should not be an issue for most diversity manipulations, as they are conducted at high evenness levels by virtue of using a replacement series design. Evenness does become a relevant issue when considering diversity change outside

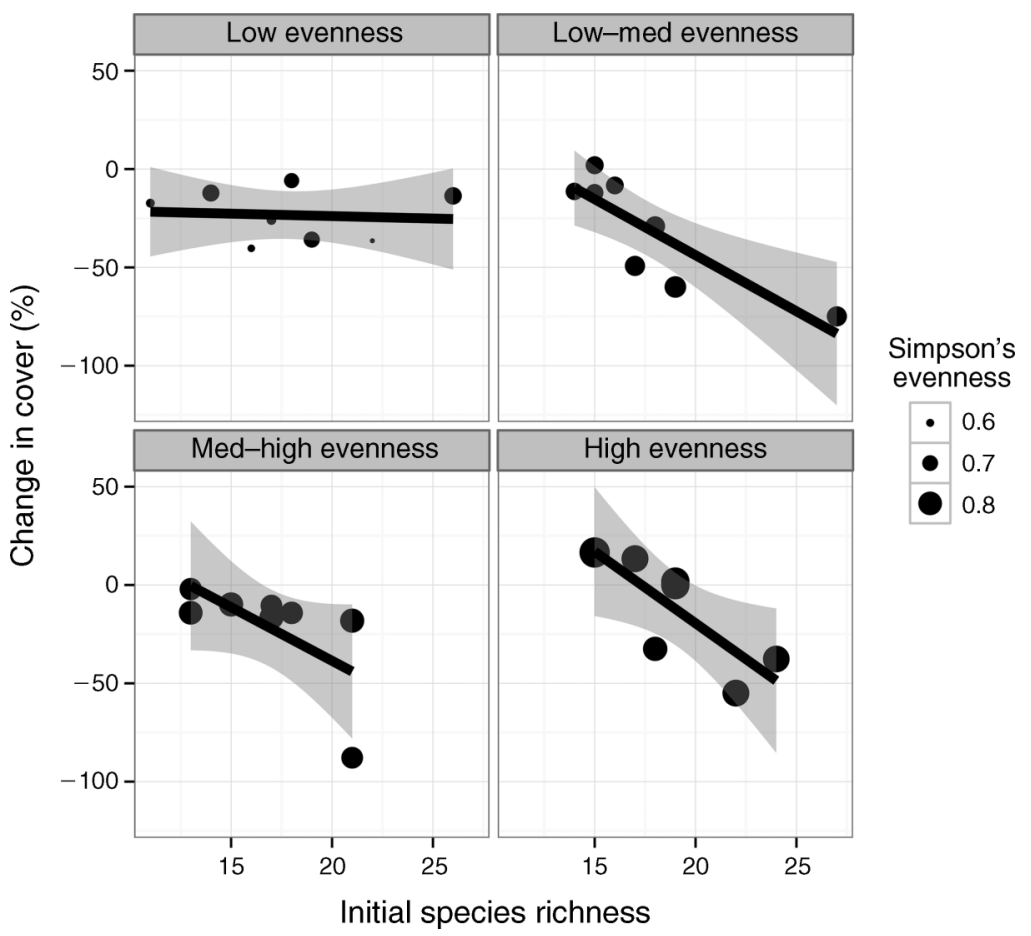

FIG. 3. Change in cover plotted against initial species richness for the low urchin density experiment. Data are split into four plots with each panel representing a subset of the data split evenly into four groups by sessile species evenness. Point size is proportion to sessile species evenness. Linear models were fit separately for each panel for visualization of the evenness $\times$ species richness interaction effect. Gray fill represents one standard error around the fitted line. 
of a controlled laboratory or mesocosm setting. We know that nonrandom species assemblages skewed in evenness by natural (or human-caused) processes can influence diversity's effect on a variety of ecosystem functions (Bracken et al. 2008, 2011). Therefore, in order to translate predictions from controlled experiments examining the consequences of diversity loss into predictions of real change in nature, we need to understand how the drivers of global change will alter evenness and how dependent the effects of diversity are on the equitable distribution of biomass among species in a community.

This translation of results of small-scale, mesocosmstyle manipulations to examinations of the effects of changes in biodiversity on ecosystem function in the natural world is one of the great challenges of biodiversity-ecosystem-function research (Cardinale et al. 2012). Our study is one attempt to cross this divide, with some potential limitations. We recognize the limitation of our study's design: the manipulation of urchin abundance in cages crossed against a naturally occurring gradient of species richness without controlling for species evenness. The lack of a completely orthogonal mesocosm-style design circumscribes our ability to clearly assign a mechanism behind the patterns we observed in the field. However, we view this as a necessary compromise to examine the real consequences of diversity change in a field setting in response to an environmental perturbation, in this case, the consequences of increases in sessile species diversity when the foundation species giant kelp is removed (Byrnes et al. 2011). The information criteria approach used here provides a framework for examining the relative support for different hypotheses regarding the effect of diversity under these more uncontrolled conditions as well as a means to incorporate other sources of biologically important natural variation. While this approach was not able to definitively identify the underlying mechanism for the effects of diversity in our experiment, we were able to use it to rule out the effects of any single species or functional group.

Did richness alter the impact of grazing urchins in our experiment or was its effect on change in the cover of sessile biota independent of urchins? We find the latter option unlikely over the short period of time during which we conducted our trials (i.e., not enough time for competitive exclusion) and the weight of evidence from all of our analyses. Also, most of the loss in cover was due to decreases in red and brown algae, consistent with grazing damage by sea urchins (Appendix B). Based on our results regarding evenness, we find that our results are consistent with some of the possible mechanisms that are suggested by kelp forest natural history. We acknowledge that our power was low to detect interaction effects (both richness $\times$ urchin and richness $\times$ urchin $\times$ evenness) in the low-urchin-abundance experiment due to the unplanned destruction of several cages in combination with the already less than optimal power of detection of an effect in that range of urchin densities. However, only a controlled experiment (done in the laboratory or in a contrived natural setting) testing the effects of a richness $\times$ evenness interaction on urchin grazing in the absence of Macrocystis, urchins' preferred food, can yield a definitive answer.

Given our results and the natural history of purple urchins and their prey, the balanced diet hypothesis, the toxin minimization hypothesis, or some combination of the two are plausible explanations for our observed results with respect to species evenness. Previous work provides some support for the balanced diet hypothesis. Purple urchins have been shown to display highly selective feeding in the laboratory, maximizing their fitness (Vadas 1977). The prey that purple urchins encounter in nature vary greatly in their carbon, nitrogen, and phosphorous content (Atkinson and Smith 1983) and concentrations of specific fatty acids and minerals (Khotimchenko et al. 2002). Indeed, many other species of urchins grow faster and put on more gonad weight when fed mixed diets of some sort (Larson et al. 1980, Fernandez and Boudouresque 1998, Fernandez and Pergent 1998, Vadas et al. 2000, Kennedy et al. 2007). At the same time, toxin minimization may still play a role. Many algae and sessile invertebrates in the Northeast Pacific contain chemical deterrents to grazing (Hall et al. 1973, Crews and Kho-Wiseman 1977, Estes and Steinberg 1988, Iken and Dubois 2006). Deterrent compounds are relatively low in concentration in the brown algae that form the bulk of the diet of sea urchins found in the Northeast Pacific (Estes and Steinberg 1988). Therefore, the chemical defenses in other sessile species may have played a role in observed patterns of urchin consumption. Whether the two mechanisms acted separately, together, or in concert with some other mechanism we have not here considered, cannot be directly ascertained from this series of field experiments alone.

In general, our results suggest a need to understand the larger context of factors altering both prey diversity and the local environment, as the two likely interact. This dependence of strong consumer pressure on additional factors is particularly strong in urchindominated systems (Bulleri et al. 2011). We have shown that in a system where prey diversity is enhanced by the same mechanisms that could lead to increases in the active foraging of generalist consumers, storms that remove giant kelp (Harrold and Reed 1985, Byrnes et al. 2011), diversity could reduce resistance to consumption. Our results also suggest that the effects of prey species richness can change due to shifts in community evenness, a potentially more common outcome of the ecological effects of global change. Last, if global change leads to intense consumer outbreaks, changes in diversity may prove relatively unimportant in the face of extreme consumer densities. These variable effects of prey diversity on consumption pressure are all predictable, but require a coupling of ecological theory with natural history to make valuable decisions for the future of ecosystem management. 


\section{ACKNOWLEDGMENTS}

We thank Clint Nelson, Gabe Rodriguez, Shannon Harrer, Christine Donahue, Matt Silbert, Jocelyn Christie, and Matt Foster for help in the field. Russ Schmitt and Sally Holbrook provided helpful comments on the project design. Comments by two anonymous reviewers greatly improved the manuscript. Funding was provided by the US National Science Foundation in support of the Santa Barbara Coastal LTER.

\section{Literature Cited}

Arkema, K. K., D. C. Reed, and S. C. Schroeter. 2009. Direct and indirect effects of giant kelp determine benthic community structure and dynamics. Ecology 90:3126-3137.

Atkinson, M. J., and S. V. Smith. 1983. C:N:P ratios of benthic marine plants. Limnology and Oceanography 28:568-574.

Balvanera, P., A. B. Pfisterer, N. Buchmann, J.-S. He, T. Nakashizuka, D. Raffaelli, and B. Schmid. 2006. Quantifying the evidence for biodiversity effects on ecosystem functioning and services. Ecology Letters 9:1146-1156.

Behrens, M. D., and K. D. Lafferty. 2004. Effects of marine reserves and urchin disease on southern Californian rocky reef communities. Marine Ecology Progress Series 279:129139.

Bracken, M. E. S., S. E. Friberg, C. A. Gonzalez-Dorantes, and S. L. Williams. 2008. Functional consequences of realistic biodiversity changes in a marine ecosystem. Proceedings of the National Academy of Sciences USA 105:924-928.

Bracken, M. E. S., E. Jones, and S. L. Williams. 2011. Herbivores, tidal elevation, and species richness simultaneously mediate nitrate uptake by seaweed assemblages. Ecology 92:1083-1093.

Bruno, J. F., K. E. Boyer, J. E. Duffy, and S. C. Lee. 2008. Relative and interactive effects of plant and grazer richness in a benthic marine community. Ecology 89:2518-2528.

Bulleri, F., C. Cristaudo, T. Alestra, and L. Benedetti-Cecchi. 2011. Crossing gradients of consumer pressure and physical stress on shallow rocky reefs: a test of the stress-gradient hypothesis. Journal of Ecology 99:335-344.

Burnham, K. P., and D. R. Anderson. 2002. Model selection and multimodel inference: a practical information-theoretic approach. Springer-Verlag, Berlin, Germany.

Byrnes, J. E., D. C. Reed, B. J. Cardinale, K. C. Cavanaugh, S. J. Holbrook, and R. J. Schmitt. 2011. Climate driven increases in storm frequency simplify kelp forest food webs. Global Change Biology 17:2513-2524.

Cardinale, B. J., et al. 2012. Biodiversity loss and its impact on humanity. Nature 486:59-67.

Cardinale, B. J., K. Matulich, D. U. Hooper, J. E. Byrnes, J. E. Duffy, L. Gamfeldt, P. Balvanera, M. I. O'Connor, and A. Gonzalez. 2011. The functional role of producer diversity in ecosystems. American Journal of Botany 98:572-592.

Cardinale, B. J., D. S. Srivastava, J. E. Duffy, J. P. Wright, A. L. Downing, M. Sankaran, and C. Jouseau. 2006. Effects of biodiversity on the functioning of trophic groups and ecosystems. Nature 443:989-992.

Crews, P., and E. Kho-Wiseman. 1977. Acyclic polyhalogenated monoterpenes from the red algae Plocamium violaceum. Journal of Organic Chemistry 42:2812-2815.

Duffy, J. E. 2009. Why biodiversity is important to the functioning of real-world ecosystems. Frontiers in Ecology and the Environment 7:437-444.

Duffy, J. E., P. J. Richardson, and K. E. France. 2005. Ecosystem consequences of diversity depend on food chain length in estuarine vegetation. Ecology Letters 8:301-309.

Edwards, K. F., K. M. Aquilino, R. J. Best, K. L. Sellheim, and J. J. Stachowicz. 2010. Prey diversity is associated with weaker consumer effects in a meta-analysis of benthic marine experiments. Ecology Letters 13:194-201.

Estes, J. A., and P. D. Steinberg. 1988. Predation, herbivory, and kelp evolution. Paleobiology 14:19-36.
Fernandez, C., and C. F. Boudouresque. 1998. Evaluating artificial diets for small Paracentrotus lividus (Echinodermata: Echinoidea. Pages 651-657 in R. Mooi and M. Telford, editors. Echinoderms: San Francisco. Proceedings, 9th International Echinoderm Conference. A. A. Balkema, Rotterdam, The Netherlands.

Fernandez, C., and G. Pergent. 1998. Effect of different formulated diets and rearing conditions on growth parameters in the sea urchin Paracentrotus lividus. Journal of Shellfish Research 17:1571-1582.

Fox, J. W. 2004. Effects of algal and herbivore diversity on the partitioning of biomass within and among trophic levels. Ecology 85:549-559.

Freeland, W. J., and D. H. Janzen. 1974. Strategies in herbivory by mammals: the role of plant secondary compounds. American Naturalist 108:269-289.

Gamfeldt, L., H. Hillebrand, and P. R. Jonsson. 2005. Species richness changes across two trophic levels simultaneously affect prey and consumer biomass. Ecology Letters 8:696703.

Hall, S. S., D. J. Faulkner, J. Fayos, and J. Clardy. 1973. Oppositol, a brominated sesquiterpene alcohol of a new skeletal class from the red alga, Laurencia subopposita. Journal of the American Chemical Society 95:7187-7189.

Harrold, C., and J. S. Pearse. 1987. The ecological role of echinoderms in kelp forests. Pages 137-223 in M. Jangoux and J. M. Lawrence, editors. Echinoderm studies. A. A. Balkema, Rotterdam, The Netherlands.

Harrold, C., and D. C. Reed. 1985. Food availability, sea urchin grazing, and kelp forest community structure. Ecology $66: 1160-1169$.

Hector, A., T. Bell, Y. Hautier, F. Isbell, M. Kéry, P. B. Reich, J. van Ruijven, and B. Schmid. 2011. BUGS in the analysis of biodiversity experiments: species richness and composition are of similar importance for grassland productivity. PLoS ONE 6:e17434.

Hillebrand, H., D. M. Bennett, and M. W. Cadotte. 2008. Consequences of dominance: a review of evenness effects on local and regional ecosystem processes. Ecology 89:1510 1520 .

Hillebrand, H., and B. J. Cardinale. 2004. Consumer effects decline with prey diversity. Ecology Letters 7:192-201.

Hillebrand, H., and B. Matthiessen. 2009. Biodiversity in a complex world: consolidation and progress in functional biodiversity research. Ecology Letters 12:1405-1419.

Hooper, D. U., et al. 2005. Effects of biodiversity on ecosystem functioning: a consensus of current knowledge. Ecological Monographs 75:3-35.

Hughes, A. R., and J. J. Stachowicz. 2004. Genetic diversity enhances the resistance of a seagrass ecosystem to disturbance. Proceedings of the National Academy of Sciences USA 101:8998-9002.

Iken, K., and A. Dubois. 2006. Kelp-grazer interactions in Kachemak Bay, Alaska: grazing activity and chemical defenses and resource allocation in selected kelp species. Final Report 407. North Pacific Research Board, Anchorage, Alaska, USA.

Illius, A. W., D. A. Clark, and J. Hodgson. 1992. Discrimination and patch choice by sheep grazing grass-clover swards. Journal of Animal Ecology 61:183-194.

Kennedy, E. J., S. M. C. Robinson, G. J. Parsons, and J. D. Castell. 2007. Effect of dietary minerals and pigment on somatic growth of juvenile green sea urchins, Strongylocentrotus droebachiensis. Journal of the World Aquaculture Society 38:36-48.

Khotimchenko, S. V., V. E. Vaskovsky, and T. V. Titlyanova. 2002. Fatty acids of marine algae from the Pacific coast of North California. Botanica Marina 45:17-22.

Larson, B. R., R. L. Vadas, and M. Keser. 1980. Feeding and nutritional ecology of the sea urchin Strongylocentrotus drobachiensis in Maine, USA. Marine Biology 59:49-62. 
Levenbach, S. 2008. Grazing intensity influences the strength of an associational refuge on temperate reefs. Oecologia 159: 181-190.

Marsh, K. J., I. R. Wallis, S. McLean, J. S. Sorensen, and W. J. Foley. 2006. Conflicting demands on detoxification pathways influence how common brushtail possums choose their diets. Ecology 87:2103-2112.

McCullagh, P., and J. A. Nelder. 1989. Generalized linear models. Second edition. Chapman and Hall, Boca Raton, Florida, USA.

O'Hara, R. B., and D. J. Kotze. 2010. Do not log-transform count data. Methods in Ecology and Evolution 1:118-122.

Parker, J. D., J. P. Salminen, and A. A. Agrawal. 2010. Herbivory enhances positive effects of plant genotypic diversity. Ecology Letters 13:553-563.

Pennings, S. C., M. T. Nadeau, and V. J. Paul. 1993. Selectivity and growth of the generalist herbivore Dolabella auricularia feeding upon complementary resources. Ecology 74:879-890.

Pfisterer, A. B., M. Diemer, and B. Schmid. 2003. Dietary shift and lowered biomass gain of a generalist herbivore in speciespoor experimental plant communities. Oecologia 135:234241.

R Development Core Team. 2011. R: a language and environment for statistical computing. Version 2.13. R Foundation for Statistical Computing, Vienna, Austria. www.r-project.org

Rapport, D. J. 1971. An optimization model of food selection. American Naturalist 105:575-587.

Rogosic, J., R. E. Estell, D. Skobic, and S. Stanic. 2007. Influence of secondary compound complementarity and species diversity on consumption of Mediterranean shrubs by sheep. Applied Animal Behaviour Science 107:58-65.

Scherber, C., A. Milcu, S. Partsch, S. Scheu, and W. W. Weisser. 2006. The effects of plant diversity and insect herbivory on performance of individual plant species in experimental grassland. Journal of Ecology 94:922-931.
Schmidt, K. A., and R. S. Ostfeld. 2001. Biodiversity and the dilution effect in disease ecology. Ecology 82:609-619.

Smith, B., and J. B. Wilson. 1996. A consumer's guide to evenness indices. Oikos 76:70-82.

Srivastava, D. S., B. J. Cardinale, A. L. Downing, J. E. Duffy, C. Jouseau, M. Sankaran, and J. P. Wright. 2009. Diversity has stronger top-down than bottom-up effects on decomposition. Ecology 90:1073-1083.

Stachowicz, J. J., J. F. Bruno, and J. E. Duffy. 2007. Understanding the effects of marine biodiversity on communities and ecosystems. Annual Review of Ecology, Evolution, and Systematics 38:739-766.

Steiner, C. F. 2001. The effects of prey heterogeneity and consumer identity on the limitation of trophic-level biomass. Ecology 82:2495-2506.

Tilman, D., J. Knops, D. Wedin, P. Reich, M. Ritchie, and E. Siemann. 1997. The influence of functional diversity and composition on ecosystem processes. Science 277:1300-1302.

Vadas, R. L. 1977. Preferential feeding: an optimization strategy in sea urchins. Ecological Monographs 47:337-371.

Vadas, R. L., B. Beal, T. Dowling, and J. C. Fegley. 2000. Experimental field tests of natural algal diets on gonad index and quality in the green sea urchin, Strongylocentrotus droebachiensis: a case for rapid summer production in postspawned animals. Aquaculture 182:115-135.

Wahl, M., and M. E. Hay. 1995. Associational resistance and shared doom: effects of epibiosis on herbivory. Oecologia 102:329.

Wang, L., D. Wang, Z. He, G. Liu, and K. C. Hodgkinson. 2010. Mechanisms linking plant species richness to foraging of a large herbivore. Journal of Applied Ecology 47:868-875.

Worm, B., et al. 2006. Impacts of biodiversity loss on ocean ecosystem services. Science 314:787-790.

Wyckmans, M., V. A. Chepurnov, A. Vanreusel, and M. De Troch. 2007. Effects of food diversity on diatom selection by harpacticoid copepods. Journal of Experimental Marine Biology and Ecology 345:119-128.

\section{Supplemental Material}

\section{Appendix A}

Urchin treatment assignments (Ecological Archives E094-147-A1).

\section{Appendix B}

Change in cover of different taxonomic groups of organisms plotted against species richness from the low-urchin-density trial (Ecological Archives E094-147-A2).

\section{Supplement}

R code used for all analyses and figures in the manuscript (Ecological Archives E094-147-S1). 